\title{
4 \\ TECNOLOGIAS LIMPAS, IMPASSES SOCIOAMBIENTAIS E A LUTA ORGANIZADA DA CATEGORIA DE CATADORES/AS
}

\author{
Clean technologies, social and environmental impasses and the organized fight of the \\ category of waste pickers
}

Geiziane Silva Cotrim*

https://orcid.org/0000-0002-5283-8310

\author{
Juliane Feix Peruzzo ** \\ https://orcid.org/0000-0001-9834-0334
}

\begin{abstract}
RESUMO
O artigo tem por finalidade refletir sobre o trabalho de catadores/as na cadeia produtiva da reciclagem atividade marcada pela exploração, informalidade, desproteção social e dominação dos que controlam o processo de industrialização. Buscamos enfatizar as resistências e lutas vividas para garantia de direitos, e, sobretudo, às denúncias sobre o uso das tecnologias limpas, que vêm apresentando contradições e interferências no trabalho da categoria. Trata-se de uma pesquisa teórica, com base em estudos bibliográficos e documentais. Neste artigo, objetivamos particularizar, na esteira do trabalho da reciclagem do lixo/resíduos, a atual ofensiva do capital, agora, na sua fase de regime de acumulação financeirizado - a apropriação dos resíduos sólidos urbanos por empresas privadas de incineração e aterramento - cujo mote é produzir energia limpa, mas que em última instância é geradora de créditos de carbono - o grande negócio do mercado do gerenciamento de lixo/resíduos. Buscamos também decifrar a chamada economia verde - e, a guisa de algumas conclusões, indicamos ser, esta, a ideologia que sustenta esse nicho de acumulação que dispensa o trabalho dos catadores/as e ainda usurpa deles/as a matéria-prima geradora de renda mínima que é meio ou complemento da sua reprodução social.
\end{abstract}

\section{PALAVRAS-CHAVE}

Questão ambiental. Financeirização. Tecnologias limpas. Resíduos sólidos. Catadores/as de recicláveis.

\section{ABSTRACT}

This extract aims to mirror on the research of waste pickers in the recycling production chain, an activity marked by exploitation, informality, lack of social protection and domination of those who control the

\footnotetext{
* Assistente Social. Mestra em Serviço Social pela Universidade Federal de Pernambuco (UFPE). Assistente Social do Núcleo de Atenção à Saúde do Adolescente (NASA), em transição para o Centro de Atenção Psicossocial Infantojuvenil - (CAPSi, Maranguape, Brasil). Praça Emílio Russel, s/n, Maranguape I, Paulista (PE), CEP.: 53441-360. E-mail: geiziane_cotrim@hotmail.com.

** Assistente Social. Doutora em Serviço Social. Docente da Graduação e Pós-Graduação do Departamento de Serviço Social da Universidade Federal de Pernambuco (UFPE, Recife, Brasil). Av. Prof. Moraes Rego, 1235, Cidade Universitária, Recife (PE), CEP: 50670-901. E-mail: peruzzo.juliane@gmail.com.
}

DOI 10.22422/temporalis.2021v21n41p397-414

\begin{tabular}{|l|l}
\hline$(\mathrm{cc}) \overline{\mathrm{BY}}$ \\
\hline
\end{tabular} Commons Atribuição 4.0 Internacional (https://creativecommons.org/licenses/by/4.o/deed.pt_BR), que permite copiar e redistribuir o material em qualquer suporte ou formato, bem como adaptar, transformar e criar a partir deste material para qualquer fim, mesmo que comercial. O licenciante não pode revogar estes direitos desde que você respeite os termos da licença. 
industrialization process. We seek to emphasize their resistance and struggles in maintain rights, and, on top of that, the complaints about the use of clean technologies "that execute the contradictions and interferences in the work their job category. It is a theoretical research, based on bibliographic and documental studies. In this article, we aim to point out, as eyewitnesses of the garbage/waste recycling work, whose current incursion of capital, now in its phase of an increasing funded regime - the provision of solid urban waste by private incineration and landfill companies - whose motto is to produce "clean energy" but which ultimately generates carbon credits - the big business of the waste/waste management market. We also seek to decipher a so-called "green economy" - and, the way some tools work out. We indicate that this is the ideology that keeps this niche of accumulation that dispenses with the work of collectors and even take over from them the raw material that generates minimum income that is a means or complement to their social reproduction.

\section{KEYWORDS}

Environmental issue. Funding. Clean technologies. Solid waste. Waste pickers.

Submetido em: 22/3/2021.

Aceito em: 17/6/2021.

\section{INTRODUÇÃO}

A questão do lixo/resíduos sólidos ${ }^{1}$ ganhou destaque e maior evidência quando, no limite da ordem destrutiva do capital, a questão ambiental passou a ter agenda na esfera do Estado e, especialmente, quando a reciclagem entrou no circuito das relações de valorização no mercado. Importante destacar que se compreende por questão ambiental a insuficiência metabólica da natureza em prover recursos necessários à reprodução da vida, bem como absorver as mazelas a ela impostas perante o quadro de destrutividade firmado nas relações de produção e reprodução do capital (SILVA, 2010).

Diante disso, a reciclagem não é uma prática inovadora da sociabilidade capitalista, pois a atividade de reaproveitamento de resíduos existe há cerca de cinco mil anos e, em sua essência, representa tanto uma resposta adaptativa à escassez, como se configura em uma atividade na qual os indivíduos e as sociedades tentam fazer o uso mais eficiente dos recursos (MEDINA, 1999). Contudo, com os processos de degradação intensificados devido à produção destrutiva, nos dizeres de Mészáros (2015), diante do contexto do capital financeirizado, a reciclagem passou a ser exigida e fomentada de modo mais contundente e sob duas facetas interligadas. A primeira se direciona aos benefícios às diversas formas de vida, que, de fato, a prática pode proporcionar, como a redução da extração dos recursos naturais para fabricação de novas mercadorias, poupando, assim, a água e a energia no processo, além de reduzir a poluição de diversos ecossistemas (BRASIL, 2021).

A segunda face, por sua vez, situa-se sob o signo da lucratividade ordenada na cadeia produtiva da reciclagem compreendida pelas etapas de descarte, coleta, triagem e comercialização de Resíduos Sólidos Urbanos (RSU) 2, que, antes sem valor algum, passaram a ser convertidos em um novo objeto de interesse mercantil. Essa mediação, no

\footnotetext{
${ }^{1}$ Quanto aos termos lixo e 'resíduos sólidos', cabe aqui uma diferenciação destacada por Grimberg (2007, p. 11) o qual indica que "quando são misturados restos de alimentos, embalagens descartadas e objetos que não servem mais, torna-se lixo e devem ter como destino ambientalmente adequado o aterro sanitário. Esses mesmos materiais, quando disponibilizados separadamente para a coleta seletiva (resíduos secos e úmidos), tornam-se materiais recicláveis".

${ }^{2}$ A Política Nacional de Resíduos Sólidos (BRASIL 2010) compreende os RSU como os resíduos domiciliares, isto é, aqueles originários de atividades domésticas em residências, como também os resíduos de limpeza urbana, quaisquer sejam, os originários da varrição, limpeza de logradouros e vias públicas, bem como de outros serviços de limpeza.
}

Temporalis, Brasília (DF), ano 21, n. 41, p. 397-414, jan./jun. 2021. | ISSN 2238-1856 
entanto, utiliza-se de pessoas desempregadas ou parcialmente empregadas, denominadas catadores/as de recicláveis, que vivem e trabalham individualmente ou coletivamente nessa cadeia de valor, cuja "[...] compra e venda da força de trabalho, são encobertas na forma de compra e venda de mercadorias [...]" (MOTA; SILVA; VALENÇA, RODRIGUES e BEZERRA; 2005, p. 8).

Portanto, a notoriedade da reciclagem foi gestada no seio da ideologia do dito desenvolvimento sustentável no último quartel do século $\mathrm{XX}$, que se delineou em um contexto de crítica ao desenvolvimentismo do pós-guerra e tentou aplacar a coexistência do crescimento econômico e do desenvolvimento humano, aliados à utilização racional dos recursos naturais como medidas de enfrentamento à questão ambiental (SILVA, 2010). Todavia sabe-se que a discussão sobre o desenvolvimento sustentável traz consigo a contradição intrínseca ao tentar conciliar uma proposta economicamente, socialmente e ambientalmente adequada a um sistema altamente destrutivo que tem como premissas a expansão econômica, a usurpação do meio ambiente e a produção de pobreza, cujas determinações históricas do processo destrutivo são ignoradas (MOTA; SILVA, 2009).

Nesse contexto, a ênfase na reciclagem ganha destaque, pois, ao não entrar em conflito com os interesses do capital, confere ao próprio sistema altos graus de legitimidade social ao contribuir ideologicamente com o discurso de uma sociedade ambientalmente limpa, sustentável e geradora de emprego, mesmo que, em sua essência, apresente contradições, além de necessitar de determinados segmentos pauperizados e precarizados da classe trabalhadora para sua efetivação. Entrecruza-se aqui um problema social diretamente vinculado às problemáticas dos RSUs, o que se torna o pilar sustentado por toda a cadeia produtiva da reciclagem.

Ratificando essa perspectiva, o relatório O que é um desperdício 2.0: um panorama global da gestão de resíduos sólidos para 2050 (KAZA; YAO; BHADA-TATA e WOERDEN, 2018) publicado pelo Banco Mundial, informa que estão envolvidos nas atividades de reciclagem no mundo mais de 15 milhões de trabalhadores/as. Desse quantitativo, quatro milhões estão na América Latina. Nessa perspectiva, a Organizações das Nações Unidas (ONU, 2010) citada pela rede global Women in Informal Employment: Globalizing and Organizing (WIEGO WOMEN IN INFORMAL EMPLOYMENT: GLOBALIZING AND ORGANIZING, 2015) ${ }^{3}$, informa que nos países periféricos, os/as catadores/as se tornaram os principais responsáveis pela reciclagem de resíduos, realizando de $50 \%$ a $100 \%$ da coleta.

Exemplificando esse cenário no Brasil, a coleta seletiva4, que era inexpressiva até os anos 1980 , generalizou-se por diversas cidades nesse período. A condição para esse alastrar, não coincidentemente, foi estabelecida mediante o ingresso de milhares de trabalhadores/as na cata de recicláveis, haja vista que:

\footnotetext{
${ }^{3}$ Tem como tradução: Mulheres no Emprego Informal: globalizando e organizando, que segundo a sua página na internet, refere-se a uma rede de indivíduos e instituições de diversas partes do mundo com o propósito de apoiar e fortalecer as organizações de trabalhadores; unir as organizações; realizar e patrocinar pesquisas, como também auxiliar no desenvolvimento e melhoramento de estatísticas oficiais sobre o emprego informal.

${ }^{4}$ Refere-se à coleta de resíduos previamente segregados conforme sua constituição ou composição a serem adequadamente tratados, especialmente com a participação de cooperativas ou outras formas de associação de catadores de materiais reutilizáveis e recicláveis formadas por pessoas físicas de baixa renda (PNRS, 2010).
} 
[...] o recolhimento e a separação dos resíduos se mostraram uma tarefa viável e de baixo custo. [...] Essa força de trabalho surgiu composta de trabalhadores sem contrato e com uma produtividade que pudesse ser definida pelo pagamento por produção: uma população desancada do mercado de trabalho e sem atributos para retornar às ocupações formais. Estes fatores garantiram, em grande parte, $\mathrm{o}$ crescimento do setor de reciclagem de modo a tornar os preços dos materiais reciclados cada vez mais próximos dos materiais não reciclados, o que efetivamente pôde ser verificado nos últimos anos da década de 1990 (BOSI, 2008, p. 104).

Já no início dos anos 2000 , os/as catadores/as passaram rapidamente a cumprir $89 \%$ do trabalho na cadeia produtiva da reciclagem, restando $11 \%$ do serviço aos atravessadores 5 e à indústria recicladora (MOVIMENTO NACIONAL DE CATADORES DE RECICLÁVEIS, 2009, apud Severi, 2014). Essa situação se mantém atualmente com mais de um milhão e meio de catadores/as atuando nas ruas, em aterros e lixões, além de cooperativas e associações, sendo, portanto, responsáveis por $90 \%$ de tudo que é reciclado no Brasil, mas, contraditoriamente, ficando apenas com $11 \%$ dos valores obtidos pela reciclagem, pois a maior concentração (mais de $88 \%$ ) é usurpada pelos atravessadores e pelas indústrias recicladoras, segundo informações do $M N C R$ s/d apud Relatório de Avaliação por Área de Gestão de Resíduos Sólidos 2017 e do MNCR (2019a).

Apesar de se constituírem como a principal força de trabalho na cadeia produtiva da reciclagem a nível nacional e em outras regiões periféricas (Ásia, África e demais países da América Latina), o reconhecimento do trabalho de catadores/as, tanto socialmente quanto institucionalmente, retardou a emergir e as intervenções estatais e multilaterais só começam a ser incorporadas às suas agendas mediante reivindicações dos/as próprios/as trabalhadores/as, cujo aviltamento da ocupação se apresentava incoerente com o tão defendido desenvolvimento sustentável (COTRIM, 2020).

Aliada a essa luta de longa data, a categoria de catadores, cuja luta travada historicamente é contra a invisibilidade do seu trabalho, passou a esbarrar-se em mais um conflito que os afetam diretamente: a apropriação dos resíduos sólidos urbanos por empresas nos processos de gerenciamentos de resíduos, as quais fazem uso das ditas tecnologias limpas ao invés do encaminhamento desses materiais para a reciclagem.

No tocante às referidas tecnologias, Vandermerwe e Oliff (1990) as compreendem como “[...] novos processos industriais ou mesmo processos industriais já existentes, porém alterados, com o objetivo de reduzir os impactos ambientais, o consumo de matériasprimas e o consumo energético utilizado durante o ciclo produtivo" (VANDERMERWE; $\operatorname{OLIFF}(1990$, p. 10-16).

No processo de gerenciamento de resíduos sólidos são utilizadas tais tecnologias aplicadas em aterros sanitários e incineradores, conceitos a serem discriminados no decorrer do texto. Nesse contexto, o lixo e os próprios resíduos sólidos são mantidos como soluções ambientais, mas ganham novos contornos lucrativos pela via da financeirização ao serem usados como combustíveis produtores de energia limpa, isto é, energia com potencial de

\footnotetext{
${ }^{5}$ Conhecidos também como sucateiros, os atravessadores são intermediários na cadeia produtiva e compram dos catadores pequenas quantidades de materiais e revendem, em grandes volumes, às indústrias (SANTOS; DIAS; MENDONÇA; TEODÓSIO, 2011). Já as indústrias estão no topo da hierarquia dessa cadeia e se tornam as maiores beneficiadas na aquisição da lucratividade ao pouparem custos com energia, água, matéria-prima e, principalmente, força de trabalho (MOTA, SILVA, VALENÇA, RODRIGUES e BEZERRA 2005, p. 8).
} 
produção elétrica e/ou térmica, cujas matérias-primas derivam de recursos renováveis como o sol, a água, o vento e, até mesmo, pelos resíduos sólidos urbanos, e, portanto, defendida como não geradora de poluentes na atmosfera como acontece com combustíveis fósseis.

Para a Ana Lee Tan, integrante da Aliança Global para Alternativas à Incineração ${ }^{6}$ (GAIAem Inglês, 2009 - tradução nossa), o uso dessas práticas são contraditórias e tornam-se incompatíveis com a aparente proposta. Na essência desse debate, portanto, está o fato de que tais mecanismos tendem a desestimular a redução de lixo/resíduos no mundo, uma vez que necessitam se manter em grandes quantidades, pois há relação direta com a lucratividade.

É necessário pontuarmos aqui que em nenhuma medida defendemos o trabalho com e no lixo/resíduos como alternativa de sobrevivência para indivíduos e famílias, pois compreendemos que este seja um ofício extenuante e abjeto, consolidado como expressão do desemprego e da desproteção social do Estado. Também destacamos que compactuamos com a ideia de se ter alternativas tecnológicas para a resolução da problemática dos resíduos urbano, pois a ciência deve se voltar para impasses como esses, desde que as ações também se direcionem para o cerne da questão como o produtivismo, o consumismo e a descartabilidade exacerbada. Desse modo, a intenção, aqui, é problematizar e refletir até que ponto essas tecnologias, pautadas no circuito mercantil e financeiro, resolvem os problemas em sua integralidade ou podem agravar conflitos socioambientais por terem como premissa e finalidade o lucro.

Diante disso, estruturou-se o texto em dois tópicos. No primeiro, buscou-se discorrer sobre o processo de gerenciamento do lixo/resíduos inseridos no circuito financeirizado do capital, com suas bases assentadas no apoio e aval do Estado. No segundo, trouxemos os impactos ocasionados aos/às catadores/as frente a esse universo de contradições e também um breve apanhado da luta da categoria organizada em prol dos seus direitos. Para a construção do exposto, valemo-nos de pesquisa teórica, com abordagem exploratória, através da qual, além da revisão da literatura com base em fontes bibliográficas, recorremos a documentos, relatórios e organizações nacionais e internacionais que abordam essa problemática.

\section{GERENCIAMENTO DO LIXO/RESÍDUOS SÓLIDOS NA ROTA DA FINANCEIRIZAÇÃO}

Perante a permanente necessidade de expansão, o capitalismo pós anos 1970, fase de ampliação da financeirização, cuja marca foi o capital produtivo subsumido ao capital fictício, reafirmou a sua incessante busca de novos espaços de valorização. Nesse contexto, a problemática do aquecimento global ganhou centralidade nos debates ordenados pelos Organismos Multilaterais no fim do século XX e início do século XXI.

O uso intensivo das principais matérias-primas utilizadas ao longo da chamada produção de mercadorias de base fordista/taylorista no contexto da reestruturação produtiva quaisquer sejam, a queima sistemática de combustíveis fósseis como o carvão mineral e o

\footnotetext{
${ }^{6}$ Organização mundial essa composta por mais de 800 grupos de base e indivíduos em mais de 90 países.
}

Temporalis, Brasília (DF), ano 21, n. 41, p. 397-414, jan./jun. 2021. | ISSN 2238-1856 
petróleo tornaram-se uma das maiores fontes de emissões de gases de efeito estufa (GEE) ${ }^{7}$ na atmosfera, especialmente o dióxido de carbono $\left(\mathrm{CO}_{2}\right)$, que é classificado como um dos maiores causadores da elevação da temperatura no mundo.

Ao ser considerado como um dos grandes vilóes do aquecimento global atualmente, algumas práticas incidentes sobre $\mathrm{O}^{\mathrm{CO}_{2}}$ foram legitimadas e incentivadas a partir da

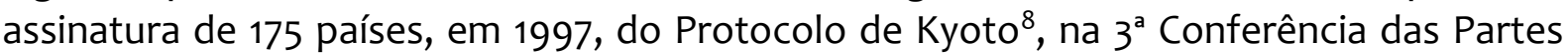
(COP-3), realizada no Japão. O Protocolo propôs mecanismos para auxiliar os países a cumprirem suas metas ambientais, dentre elas, a preconização do Mecanismo de Desenvolvimento Limpo ( $\mathrm{MDL}$ ) sobre o qual se estabeleceu um mercado mundial de Reduções Certificadas de Emissões (RCE), conhecido também como Créditos de Carbono. De forma objetiva, Rocha (2003) esclarece como funciona essa tática:

\begin{abstract}
A proposta do MDL consiste em que cada tonelada de $\mathrm{CO}_{2}$ deixada de ser emitida ou retirada da atmosfera por um país em desenvolvimento poderá ser negociada no mercado mundial, criando um novo atrativo para redução das emissões globais. Os países desenvolvidos estabelecerão em seus territórios metas para redução de $\mathrm{CO}_{2}$ junto aos principais emissores. As empresas que não conseguirem (ou não desejarem) reduzir suas emissões poderão comprar Certificados de Emissões Reduzidas [CER] em países em desenvolvimento e usá-los para cumprir suas obrigações (ROCHA, 2003, p. 9).
\end{abstract}

Dessa maneira, estruturou-se, assim, um comércio mundial desse Crédito compreendido como um equivalente universal a ser trocado no mercado financeiro entre os países. Essa estratégia, apesar de considerável, tornou-se uma inconveniência à medida que reduziu as problemáticas ambientais às emissões de carbono e, portanto, todos os esforços estatais e multilaterais se voltaram para a implementação de medidas capazes de mitigá-las, ao passo que ignoraram as determinações que originam tais poluentes. Dentre os projetos financiados pelos países centrais, maiores produtores de $\mathrm{CO}_{2}$ no mundo, para que os países periféricos poupassem esse temido gás, estão aqueles que podem gerar as chamadas energias limpas, através das técnicas de aterramento e incineração.

A prática de aterramento acontece em aterros sanitários e aterros controlados. O primeiro possui um conjunto de sistemas e medidas necessárias para a proteção do meio ambiente contra danos e degradações, portanto é considerado um mecanismo adequado de disposição do lixo. Já o segundo, os aterros controlados, diferem-se dos sanitários por não possuírem esses sistemas, pois apenas dispõe de um espaço no qual o lixo é depositado e aterrado, sendo, assim, considerado inadequado para a disposição de resíduos pelos danos causados ao meio ambiente (ASSOCIAÇÃO BRASILEIRA DE EMPRESAS DE LIMPEZAS PÚBLICAS DE RESÍDUOS SÓLIDOS ESPECIAIS, 2017). Hoje, existem aterros sanitários que possuem tecnologias capazes de recuperar energia para eletricidade e aquecimento, o que acontece pela geração do biogás resultante da decomposição anaeróbia do lixo no interior do aterro (AGÊNCIA AMBIENTAL EUROPEIA, 2011 apud POLZER, 2017; EIGENHEER, 2009).

\footnotetext{
7 De acordo com Protocolo de Kyoto (1997), os seis principais gases causadores do efeito estufa são: dióxido de carbono $\left(\mathrm{CO}_{2}\right)$, metano $\left(\mathrm{CH}_{4}\right)$, óxido nitroso $\left(\mathrm{N}_{2} \mathrm{O}\right)$, hexafluoreto de enxofre $\left(\mathrm{SF}_{6}\right)$, hidrofluorcarbonos (HFCs) e perfluorcarbonos (PFCs).

${ }^{8}$ A proposta é derivada da Convenção-Quadro das Nações Unidas sobre Mudanças Climáticas (UNFCC) erguida no evento Rio 92 (1992) e se refere a um tratado internacional com metas obrigatórias de redução nas emissões de GEE, especialmente o $\mathrm{CO}_{2}$ em países de economia central com cooperação dos países da periferia do capitalismo.
}

Temporalis, Brasília (DF), ano 21, n. 41, p. 397-414, jan./jun. 2021. | ISSN 2238-1856 
Quanto à incineração, essa técnica consiste em queimar os resíduos em instalações próprias para este fim, conforme as suas características materiais (CHIRICO, 2013). Durante muito tempo, a prática apresentou inconveniências ambientais (emissões de gases na atmosfera, produção de muita poeira) e, com a intensa pressão dos movimentos ecológicos, houve a substituição dos antigos incineradores para os que tendem à "poluição zero", com tecnologias de produção de energia elétrica e térmica vigentes na atualidade, conhecidas como waste to energy, isto é, recuperação energética em sua tradução (CHIRICO, 2013; POLZER, 2017).

O empenho para se conseguir fontes limpas de energia e aquecimento ganhou materialidade no auge da crise capitalista de 2008, quando o mercado necessitou encontrar outras formas de valorização. Nesse contexto, foi lançado pelo Programa das Nações Unidas para o Meio Ambiente (PNUMA) a proposta da Economia Verde, descrita como "[...] uma alternativa ao modelo econômico dominante, que exacerba as desigualdades, incentiva o desperdício, desencadeia escassez de recursos e gera ameaças generalizadas ao meio ambiente e à saúde humana" (ONU, 2015).

Observa-se, assim, uma nova roupagem da velha estratégia do capital em busca de mitigar as consequências da depredação e exploração do meio ambiente com as premissas e finalidades bem delineadas sob o viés da lucratividade. Estratégias, essas, advertidas por Layrargues (2000) como iniciativas do mercado, no que tange às soluções ambientais que ganharam impulso desde os anos 1990, quando o Ambientalismo Empresarial, expresso no chamado Sistema de Gerenciamento Ambiental (SGA), passou a direcionar o ideário do desenvolvimento sustentável.

Sob esse aspecto, Misoczky e Böhm (2012) nos informam que, mesmo havendo semelhanças com o desenvolvimento sustentável, há uma significativa diferença em relação à Economia verde: "[...] enquanto o desenvolvimento sustentável era entendido como a investida encoberta do capital sobre a natureza, a Economia verde é entendida como a investida radical e aberta do capital sobre a natureza" (MISOCZKY; BÖHM, 2012, p. 547).

Diante do predomínio da necessidade de eficiência energética, o manejo dos resíduos sólidos se torna um campo a ser apoderado pelo empresariado, com anuência do Estado, seja na facilitação de empréstimos, seja na isenção de impostos ou, até mesmo, nas negociações diretas de materiais no processo de gerenciamento de resíduos municipais. Assim, entra no rol das fontes limpas a energia proveniente de tais resíduos através dos já citados mecanismos; incineração e aterramento. Esses resíduos são eleitos como fonte de energia limpa devido a sua utilização como combustíveis para geração de eletricidade e aquecimento sem que haja liberação de gases na atmosfera. Esta ação recebe o Certificado de Redução de Emissão, proposto pelo MDL, e acarreta em um negócio de geração de valor - o Crédito do Carbono (FUNK et al., 2013 apud POLZER, 2017; NASCIMENTO; FREIRE; DANTAS; GIANSANTE, 2017).

Portanto, a utilização dessas tecnologias para a resolução da problemática do lixo/resíduos aparece como interessante e eficiente, afinal, denota a importante atuação da ciência a serviço dos impasses da nossa sociabilidade. Contudo, é preciso considerar que, nesse contexto, as alternativas são propostas pelo mercado, o qual tem o lucro como alicerce de sua existência. Isso implica minimamente em um conjunto de contradições, especialmente

Temporalis, Brasília (DF), ano 21, n. 41, p. 397-414, jan./jun. 2021. | ISSN 2238-1856 
para os trabalhadores/as catadores/as, que, por sua vez, terão lutas travadas, tanto no Brasil, como no mundo a fora, perante esse nicho lucrativo emergente.

\section{RESÍDUOS SÓLIDOS EM DISPUTA E A ORGANIZAÇÃO DA CATEGORIA DE CATADORES/AS}

Diante da apropriação dos resíduos sólidos recicláveis pelas empresas com aval do Estado, progressivamente em rota majoritária, destinada, portanto, a abastecer o mercado da recuperação energética, os efeitos já são percebidos no cotidiano dos/as catadores/as. Conforme a pesquisa realizada pela WIEGO (2014) com catadores/as da África, Ásia e América Latina, para 73\% dos entrevistados, a falta de acesso a resíduos é um problema de moderado a grande em suas regiões, sendo, portanto, uma realidade cada vez mais tangível ao processo de trabalho desse segmento.

Admitindo esse cenário, Nara Padilha, catadora da Colômbia - que trabalha desde os oito anos de idade nesse setor - em apresentação à $102^{\circ}$ Conferência Internacional do Trabalho (2013), reforçou em sua fala as consequências da disputa que enfrentam e destacou a correlação de interesses imbricados nesse processo:

[...] Os catadores sem acesso aos materiais recicláveis são como os pescadores sem peixes ou campesinos sem terra. Não podemos sobreviver se não garantir que os materiais recicláveis fiquem em nossas mãos e não em negócio capitalista de manejo de lixo que, por exemplo, incinera nossa fonte de sustento. A luta se mantém, pois as forças interessadas no despejo de nossa atividade [...] são as corporações que situam nos negócios por cima das pessoas (MOVIMENTO NACIONAL DE CATADORES DE RECICLÁVEIS, 2013, não paginado).

Nessa mesma perspectiva, a GAIA, representada pela Lee Tan (2009) em um dos documentos, posicionou-se contra as tecnologias direcionadas aos resíduos sólidos, porque, segundo a entidade, tendem a se sobrepor à reciclagem, haja vista que pode haver desestímulo na redução de lixo/resíduo no mundo, pois ele se mantém como fonte de riqueza, mas que, agora, permanece em grandes quantidades, o que desencadeia diversos impactos ambientais:

[...] Fornecer subsídios ou incentivos para a incineração incentiva os governos locais a destruir esses materiais, em vez de investir em práticas ambientalmente corretas e de conservação de energia, como reciclagem e compostagem [...]. [...] A queima desses materiais para gerar eletricidade cria uma demanda por "desperdício" e desestimula os esforços necessários para conservar recursos, reduzir embalagens e resíduos e incentivar a reciclagem e a compostagem. De acordo com a EPA dos EUA, incineradores e aterros de "waste to energy" contribuem com níveis muito mais altos de emissões de gases de efeito estufa e energia geral em todo o ciclo de vida do que a redução, reutilização e reciclagem dos mesmos materiais (GAIA, 2012).

[...] Mesmo os resíduos tecnologicamente mais avançados produzem centenas de substâncias perigosas distintas subprodutos incluindo dioxinas, metais pesados, compostos orgânicos e nanopartículas. Aterros sanitários emitem poluentes tóxicos que podem causar câncer, asma e outros efeitos graves para a saúde, podendo poluir águas subterrâneas em caso de vazamento (Lee Tan, 2009).

Além de impacto ambiental, sem a mediação do/a catador/a no processo, há também impactos sociais, como notabiliza os fragmentos de notas divulgadas em anos distintos pela GAIA: 
O financiamento do MDL para incineração e aterros atualmente representa uma perda de oportunidade de reduzir a poluição e ajudar a melhorar o bem-estar e padrões de vida de alguns dos mais pobres no mundo [...] (Lee Tan, 2009).

[...] Os incineradores exigem um enorme investimento de capital, mas oferecem relativamente poucos empregos quando comparados à reciclagem. [...] Os incineradores são o método mais caro para gerar energia e lidar com resíduos, ao mesmo tempo em que criam encargos econômicos significativos para as cidadessede [...] Os países e regiões da Europa que possuem altas taxas de incineração de lixo normalmente reciclam menos [...] (GAIA, 2012).

Ainda conforme essa Aliança Global (2012), mais de 90\% dos materiais descartados em incineradores e aterros podem ser reutilizados ou reciclados. Com o universo de disputas dos RSUs circunscritos, os/as catadores/as organizados/as mundialmente encontram nos eventos internacionais sobre mudanças climáticas ${ }^{9}$ a oportunidade de ecoar as suas principais reivindicações. Visto que, nesses eventos, estariam as grandes lideranças mundiais e diversos segmentos organizados em prol do planejamento, monitoramento, regulamentação e avaliação de temas de interesse coletivo, como o aquecimento global. Ao abordar tal temática, considera-se que há uma relação com as fontes renováveis de energias, nas quais englobam-se os resíduos, mas que, em tese, deveriam englobar os trabalhadores também. Nos referidos eventos os/as catadores/as exigiram:

- Excluir as tecnologias de eliminação de resíduos (como as incineradoras) do MDL e outros fundos climáticos, pois eles destroem materiais recuperáveis valiosos e assim retiram renda dos trabalhadores;

- Reconhecer o papel crucial que o setor da reciclagem informal desempenha na mitigação das alterações climáticas e numa economia saudável;

- Aprovar um Fundo Global para o Clima para investir em programas de recuperação de recursos que garantam meios de subsistência decentes para todos os trabalhadores e que sejam diretamente acessíveis por catadores e outros grupos da economia informal (VRYENHOEK, 2011).

A inconformidade da categoria se refere aos incentivos dados à incineração e às tecnologias de aterramentos pelo MDL, como disposição e destinação final do lixo em detrimento às ações para reciclagem. Foram apresentadas experiências nacionais e internacionais com métodos alternativos e sustentáveis de tratamento dos resíduos sólidos, sem a necessidade da incineração e do aterramento como destinos finais. Também apresentaram propostas de contratação e pagamento aos/as catadores/as por serviços prestados e perspectivas de novas áreas de geração de renda, como o tratamento dos resíduos orgânicos para recuperação do biogás (MOVIMENTO NACIONAL DE CATADORES DE RECICLÁVEIS, 2012).

\footnotetext{
${ }^{9}$ O primeiro evento a ter a participação da categoria buscando dar visibilidade a esta questão foi Conversa Sobre Mudança Climática em Bonn, na Alemanha, ocorrido em 2009. O segundo foi a Conferência das Nações Unidas sobre as Mudanças Climáticas em Copenhague, ocorrida na Dinamarca (2009). As reivindicações prosseguiram na Marcha Global do Dia de Ação, exigindo justiça climática na Conferência das Nações Unidas sobre Mudanças Climáticas, conhecida também como COP 17, em 2011. Posteriormente na conhecida como a maior Conferência realizada pela ONU, a Rio + 20, ocorrida em 2012, no Rio de Janeiro. Com a persistência da situação, as exigências são levadas, em 2015, à Convenção Quadro das Nações Unidas sobre Mudança Climática que ocorreu em Paris, na França e por último, na mais recente Assembleia da ONU para o Meio Ambiente, realizada em Nairóbi, no Quênia [2019] (COTRIM, 2020).
} 
Esses conflitos vivenciados pelos/as catadores/as em diversas regiões do globo também são experenciados no Brasil, afinal, foi o primeiro país do mundo a integrar catadores/as por meio de suas cooperativas aos Sistemas de Gestão de Resíduos Municipais, tornandose, desse modo, uma referência mundial nesse aspecto, de acordo com a ONU (2016). Além disso, o país se firmou como o primeiro do mundo a adotar um projeto do MDL em um aterro sanitário, no Rio de Janeiro, em 2004, cujos créditos de carbono foram negociados diretamente com os Países Baixos (GOIÁS, 2008).

Apesar da inserção do MDL no setor de manejo de RSU, no Brasil, erguer-se com proposições vinculadas às dimensões econômica, ambiental e social, com possíveis benefícios aos/às catadores/as. King, Gutberlet e Moreira da Silva (2016) destacam que o instrumento favorece, de fato, aos grandes projetos privados de geração de gás em aterros sanitários, com nenhum projeto direcionado à reciclagem até 2014 , último ano de sua análise.

A administração das soluções ambientais com as ditas tecnologias limpas comandadas por empresas e corporações se estruturou como tendência em demais setores, chegando, portanto, a representar $86 \%$ dos 191 projetos aprovados no Brasil, analisados por Michellis (2008). Segundo a autora, em 2007, o país se posicionou em terceiro lugar no mundo em número de projetos gerais aprovados pelo MDL. Quanto ao panorama do gerenciamento de resíduos/lixo no país, a Associação Brasileira de Empresas de Limpezas Públicas de Resíduos Sólidos Especiais (ASSOCIAÇÃO BRASILEIRA DE EMPRESAS DE LIMPEZAS PÚBLICAS DE RESÍDUOS SÓLIDOS ESPECIAIS, 2018), informa que a taxa de disposição em aterros no Brasil é altíssima (82\%) se comparada ao mundo (40\%). Do total de lixo aterrado no país, 59,1\% são direcionados a aterros sanitários e 22,9\% a aterros controlados. Ainda vão para lixões $18 \%$ dos resíduos e apenas $3 \%$ deles são, de fato, reciclados (ASSOCIAÇÃO BRASILEIRA DE EMPRESAS DE LIMPEZAS PÚBLICAS DE RESÍDUOS SÓLIDOS ESPECIAIS, 2018).

Com esse montante de RSU dispostos em aterros brasileiros, o número de projetos de geração de eletricidade por meio deles se expandiu. De 2010 a 2016, houve um aumento de $212 \%$ da capacidade instalada com relação a 2008 (DELIFNO, 2016). Fato, este, expresso na Tabela 1 abaixo, na qual podemos conferir a abundante captação de RSU pelos aterros em relação às outras unidades de processamento, inclusive pelas unidades de triagem, nas quais se executa a reciclagem pelos/as catadores/as.

Tabela 1 - Massa total de resíduos recebidos pelas unidades de processamento dos municípios participantes do Sistema Nacional de Informações sobre Saneamento (SNIS), segundo tipo de unidade e região do Brasil

\begin{tabular}{|c|c|c|c|c|c|c|}
\hline \multirow{2}{*}{$\begin{array}{l}\text { Tipo de unidade de } \\
\text { processamento }\end{array}$} & \multicolumn{5}{|c|}{$\begin{array}{l}\text { Massa recebida nas unidades de processamento por macronegiāo } \\
\text { geográflica (toneladas) }\end{array}$} & \multirow{2}{*}{$\begin{array}{c}\text { Massa total } \\
\text { recebida } \\
\text { (UP080) } \\
\text { (ton.) }\end{array}$} \\
\hline & Norte & Nordeste & Sudeste & Sul & $\begin{array}{l}\text { Centro- } \\
\text { Oeste }\end{array}$ & \\
\hline Lixão & $862.785,6$ & 3.535 .593 .2 & $500.671,1$ & $120.562,0$ & $1.152 .334,4$ & $6.171 .946,3$ \\
\hline Aterro controlado & $1.424 .404,4$ & $1.431 .848,0$ & $2.049 .322,3$ & $336.571,1$ & $574.108,6$ & $5.816 .254,4$ \\
\hline Aterro sanitário & $1.475 .756,6$ & $7.809 .454,8$ & $22.960 .701,1$ & $5.390 .966,9$ & 2.455 .264 .7 & $40.092 .144,1$ \\
\hline $\begin{array}{l}\text { Unidade de triagem } \\
\text { (galpỗo ou usina) }\end{array}$ & $85.368,8$ & $77.344,2$ & $1.608 .372,3$ & $1.228 .045,3$ & $137.900,5$ & 3.137 .031 .1 \\
\hline $\begin{array}{l}\text { Unidade de tratamento } \\
\text { por incineração }\end{array}$ & 0.0 & $5.090,0$ & 567,2 & $8.137,6$ & 0,0 & $13.794,8$ \\
\hline
\end{tabular}

Fonte: $17^{\circ}$ Diagnóstico do Manejo de Resíduos Sólidos Urbanos (2018).

Temporalis, Brasília (DF), ano 21, n. 41, p. 397-414, jan./jun. 2021. | ISSN 2238-1856 
Como podemos observar, o aterro sanitário continua sendo a forma predominante de recebimento de resíduos no país, com 12 vezes mais captação em relação às unidades de triagem, um dos locais em que trabalham os/as catadores/as na cadeia produtiva da reciclagem. Com o cenário exposto, afirma-se que a luta da categoria de catadores/as no Brasil é essencialmente travada contra o predomínio das tecnologias limpas em aterros sanitários, visto que a incineração é inexpressiva no país, sendo contemplada apenas nos Resíduos de Serviços de Saúde (RSS), ou seja, em tudo aquilo que é gerado nos serviços de saúde, como em hospitais, segundo informações da (ASSOCIAÇÃO BRASILEIRA DE EMPRESAS DE LIMPEZAS PÚBLICAS DE RESÍDUOS SÓLIDOS ESPECIAIS, 2018).

Diante do quadro apresentado, observa-se que o mercado da produção de energia tem nos aterros sanitários abastecimento suficiente para suprir a sua demanda a ponto de atrair multinacionais para o setor. Segundo a Revista Rochaforte (2015), uma filial francesa busca consolidação na América Latina a partir da planta brasileira em andamento. Esse campo promissor é apresentado pelo Plano Nacional de Energia 2030 (BRASIL, 2007), o qual aponta que, até o ano 2030, haverá um aumento de 39,3\% na produção de energia elétrica no país. Desse número, $6,4 \%$ corresponderão ao uso dos resíduos sólidos urbanos. Já o biogás em aterros e a incineração apresentam os maiores potenciais (2.600Watts e 8.440 Watts, respectivamente) na projeção para 2030.

Nesse contexto já bastante adiantado no quesito da produção de energia pelos aterros sanitários, a proposta de incineração dos resíduos não é inofensiva atualmente no Brasil. Segundo Alex Cardoso - catador e integrante do MNCR - relata ao jornal online Carta Maior (TUBINO, 2012), várias capitais do país como Recife, Porto Alegre, Manaus, Belo Horizonte e Brasília "estão com projetos de incineradores na mesa dos prefeitos", apresentando-se como uma ameaça latejante e real aos/às catadores/as.

Em notícia veiculada pelo MNCR (2016), com o título Falta material reciclável para os catadores. O que a Prefeitura tem com isso?, foi divulgado um comunicado alertando sobre a redução dos RSUs encaminhados à reciclagem em cooperativas de São Paulo, mas que se constituía como uma realidade nacional. Em relato nesse noticiário, um dos catadores desabafou: "Quando não se tem materiais para trabalhar, nossa renda baixa e alguns companheiros não conseguem suportar e param de trabalhar".

Para o MNCR (2016), apesar de haver interferência da crise, pois segundo a instituição, o consumo tende a diminuir, e, consequentemente, há diminuição dos recicláveis, os serviços públicos de limpeza ainda encaminham a maior parte dos RSUs para o aterramento no país. É importante destacar ainda outra adversidade: a gestão da coleta seletiva nas mãos da iniciativa privada, o que acaba dificultando o acesso ao material:

Os materiais do comércio estão sendo comercializados pelos próprios empresários. Está havendo concorrência com os garis e empresários e até com algumas iniciativas que bonificam os moradores em troca de recicláveis (MOVIMENTO NACIONAL DE CATADORES DE RECICLÁVEIS, 2016).

Portanto, são vários os impasses e obstáculos que têm dificultado o acesso aos RSUs pelos/as catadores/as. Os resíduos tornaram-se, no entanto, mercadoria visada por diversos segmentos, principalmente pelo empresariado, que descobriu um nicho lucrativo 
sem a necessidade da mediação direta da força de trabalho do/a catador/a. No âmbito do Estado, há um desestímulo da reciclagem em detrimento de alternativas "inovadoras" voltadas à produção de energia e aquecimento. Tendência, essa, que ganha força com a mais recente Portaria Interministerial, N 274/2019 dos Ministérios do Meio Ambiente e de Minas e Energia e do Desenvolvimento Regional aprovada e que regulamenta a utilização de incineradores no país, denominados Usina de Recuperação Energética de Resíduos Sólidos Urbanos (URE).

Dessa maneira, poderão ser encaminhados para a URE desde os resíduos de limpeza urbana aos resíduos domiciliares, isto é, mais um confisco institucional dos materiais recicláveis no país. Nesse mesmo ano, o Governo Federal também lançou o Programa Nacional Lixão Zero com objetivo de “[...] eliminar os lixões existentes no país e apoiar os municípios em soluções mais adequadas de destinação final dos resíduos sólidos, como os aterros sanitários" (BRASIL, 2019, não paginado).

Para o MNCR, ambas as ações simbolizam ataques aos direitos da categoria pelo desamparo em relação à reciclagem em detrimento dessas tecnologias, por isso está sendo levado à Comissão Interamericana de Direitos Humanos um documento que solicita audiência para tratar do risco eminente aos/às catadores/as de materiais recicláveis do Brasil frente a essas ações (MOVIMENTO NACIONAL DE CATADORES DE RECICLÁVEIS, 2019b).

A partir do que foi apresentado, podemos evidenciar que o quadro das problemáticas dos resíduos no Brasil e os seus conflitos com os/as catadores/as segue a tendência mundial, em que os materiais recicláveis, progressivamente, têm a sua rota majoritária destinada a abastecer o mercado da recuperação energética, que, imperiosamente, significa um decurso estrito de acumulação, já que os dados e informações sobre a temática evidenciam a sua insuficiência para o meio ambiente e para o social.

\section{CONCLUSÃO}

No contexto da financeirização capitalista, os resíduos sólidos tornam-se, literalmente, combustíveis para retroalimentar as engrenagens capitalistas e se firmar mais como fonte de acumulação, a alternativas sustentáveis de tecnologias voltadas à proteção das questões ambientais.

Sob os auspícios das inovações energéticas vamos encontrar, na incineração e no aterramento, questionáveis alternativas para o excesso de mercadorias descartadas. Uma vez que a lógica envolta em tais mecanismos é de que quanto mais lixo/resíduo, mais energia limpa, maior a redução de $\mathrm{CO}_{2}$ e maior montante de créditos de carbono a ser negociado no mercado mundial. Emblematicamente, as demais alternativas também vêm acarretando a usurpação dessa matéria-prima de trabalho de catadores/as, porque são negociadas diretamente com o Estado no processo de gerenciamento dos resíduos municipais.

Entretanto, ainda que de maneira muito contraditória, evidencia-se uma disputa para obtenção dos resíduos entre empresas geradoras de energia limpa e os/as catadores/as, que encontram na ocupação um meio ou complemento da sua reprodução social. Apesar disso, as maiores perdas recaem a essa categoria, porque não há incentivos para que eles 
trabalhem com proteção de direitos neste ofício, bem como não há intervenções no sentido de que substituam a atividade laborativa em que se encontram por outra.

O desmonte e a desestimulação da reciclagem de materiais, por sua vez, com total aval do Estado e fomento dos Organismos Multilaterais, denotam a espantosa capacidade do capitalismo de transformar em riqueza o que outrora se constituía como obstáculo à lucratividade. Desse modo, propõe nichos lucrativos advindos dos resíduos para além da reciclagem, por meios que inviabilizam a recuperação dos materiais descartados e que retiram a possibilidade de reaproveitamento executado por catadores/as.

Com isso podemos compreender que a lógica da destrutividade ambiental e social são as verdadeiras facetas logadas pelo ideário da economia verde, o que vem reatualizando as práticas predatórias da produção destrutiva no meio ambiente e na vida da classe trabalhadora.

Os resultados diante dessas estratégias que têm o lucro como premissa não poderiam ser outros a não ser um cenário destrutivo acarretado pelas consequências do lixo/resíduos no mundo e com impactos diretos aos dependentes dessa atividade produtiva. Apesar de tantas perdas, a luta da categoria organizada precisa se manter ativa e persistente em prol dos direitos de trabalho, renda e proteção social, junto com os demais segmentos da classe trabalhadora.

\section{REFERÊNCIAS}

ASSOCIAÇÃO BRASILEIRA DE EMPRESAS DE LIMPEZAS PÚBLICAS DE RESÍDUOS SÓLIDOS ESPECIAIS (ABRELPE). Panorama de Resíduos Sólidos no Brasil: 2018. São Paulo, set. 2018. Disponível em: http://abrelpe.org.br/pdfs/panorama/panorama_abrelpe_2017.pdf. Acesso em: 12 jul. 2018.

ASSOCIAÇÃO BRASILEIRA DE EMPRESAS DE LIMPEZAS PÚBLICAS DE RESÍDUOS SÓLIDOS ESPECIAIS (ABRELPE). Panorama de Resíduos Sólidos no Brasil: 2017. São Paulo, Disponível em: https://abrelpe.org.br/download-panorama-2016/. Acesso em: 12 jul. 2018.

BRASIL. Ministros de Estado do Meio Ambiente; Ministério de Estado de Minas e Energia; Ministério de Estado do Desenvolvimento Regional. Portaria Interministerial $\mathbf{n}^{\circ} \mathbf{2 7 4}$, de 30 de abril de 2019. Disciplina a recuperação energética dos resíduos sólidos urbanos referida no $\S 1^{\circ}$ do art. $9^{\circ}$ da Lei $n^{\circ} 12.305$, de 2010 e no art. 37 do Decreto $n^{\circ} 7.404$, de 2010. Brasília (DF), 2019. Disponível em: http://www.in.gov.br/web/dou/-/portariainterministerial-n\%C2\%BA-274-de-30-de-abril-de-2019-86235505. Acesso em: 25 maio 2019.

BRASIL. Ministério da Transparência e Controladoria - Geral da União Secretaria Federal de Controle Interno. Relatório de Avaliação por Área de Gestão de Resíduos Sólidos. [2017]. Disponível em:

file:///C:/Users/Jefferson/Downloads/906732 Relatorio Residuos solidos vers\%C3\%A3o final ASC OM\%20(2).pdf. Outubro de 2017, Brasília, DF. Acesso em 22 out. 2018. 
BRASIL. Produção de consumo sustentável. O papel de cada um. [2021]. Disponível em: https://antigo.mma.gov.br/clima/politica-nacional-sobre-mudanca-do-clima/siderurgiasustentavel/item/7657-o-papel-de-cada-um.html. Acesso em: 25 jun. 2021.

BRASIL. Lei n. 12.305 de 02 de agosto de 2010. Institui a Política Nacional de Resíduos Sólidos (PNRS). Altera a lei n.9.605, de 12 de fevereiro de 1998; e dá outras providências. Diário Oficial da República Federativa do Brasil, Poder Executivo, Brasília (DF), 2010. Disponível em: http://www.planalto.gov.br/ccivil_03/_ato2007-2010/2010/lei//12305.htm. Acesso em: 22 mar. 2019.

BRASIL. Ministério do Desenvolvimento Regional. Secretaria Nacional de Saneamento. $\mathbf{1 7}^{\mathbf{0}}$ Diagnóstico do Manejo de Resíduos Sólidos Urbanos. [2018]. Disponível em: http://www.snis.gov.br/downloads/diagnosticos/rs/2018/Diagnostico_RS2018.pdf. Acesso em: 20. ago 2019. Brasília (DF), dez. 2019.

BRASIL. Ministério de Minas e Energia. Plano Nacional de Energia 2030. Brasília (DF), 2007. Disponível em: http://www.abesco.com.br/wp-content/uploads/2015/07/PlanoNacional-Energia-2030.pdf. Acesso em: 25 abr. 2019.

BANCO MUNDIAL. O que é um desperdício 2.0 um panorama global da gestão de resíduos sólidos para 2050. [2018]. Disponível em: https://openknowledge.worldbank.org/handle/10986/30317. Acesso e: 27 nov. 2018.

BOSI. A. P. A organização capitalista do trabalho "informal": o caso dos catadores de recicláveis. Revista Brasileira de Ciências Sociais, São Paulo, v. 23, n. 67, p. 101-116, ju. 2008. Disponível em: https://www.scielo.br/scielo.php?script=sci_arttext\&pid=S010269092008000200008\&lng=en\&nrm=iso\&tlng=pt. Acesso em: 29 ago. 2018.

CHIRICO, V. D. Incineração de resíduos urbanos. Tradução Paula Mantovanini; Gandolla Mauro [S.I.], 2013.

COTRIM, S, G. Resíduos de proteção social e abundância de precarização: condições de vida e trabalho de catadores/as em uma cooperativa de reciclagem em Recife (PE). 2020. 202f. Dissertação (Mestrado em Serviço Social)-Universidade Federal de Pernambuco, Recife, 2020.

DELFINO, A. P. O aproveitamento energético dos resíduos sólidos urbanos: as causas do subaproveitamento do biogás de aterro sanitário no Brasil. 2016. Trabalho de Conclusão de Curso [Economia]. Universidade Federal do Rio de Janeiro. 2016.

EIGENHEER, E. A história do lixo: a limpeza urbana através dos tempos. Rio de Janeiro: Editora Campus, 2009.

GAIA - ALIANÇA GLOBAL PARA ALTERNATIVAS À INCINERAÇÃO. Conhece os mitos e verdades sobre a incineração de resíduos: Oito razões para dizer não à incineração. [2012]. Disponível em: https://www.no-burn.org/wp-content/uploads/Flyer-Mitos-yVerdades-portugues.pdf. Acesso em: 12 mai. 2018. 




GOIÁS (Estado). Ministério Público do Estado de Goiás. Mecanismos de Desenvolvimento Limpo - MDL. Goiânia, 2008. Disponível em:

http://www.mpgo.mp.br/portal/noticia/mecanismos-de-desenvolvimento-limpo-

mdl\#.YFiSxagKjlU. Acesso em: 28 fev. 2018.

GRIMBERG, E. Coleta seletiva com inclusão social: Fórum Lixo e Cidadania na Cidade de São Paulo. Experiência e desafios. São Paulo: Instituto Pólis, 2007. 148p. (Publicações Pólis, 49).

KING, M. F; GUTBERLET, J; MOREIRA DA SILVA, D. Contribuição de cooperativas de reciclagem para a redução de emissão de gases de efeito estufa. In: JAQUETTO, B. C; GOES, F. P. L. Catadores de materiais recicláveis: um encontro nacional. Rio de Janeiro: Instituto de Pesquisa Econômico Aplicada, 2016. p 507-528.

KAZA, S; YAO, L; BHADA-TATA, P; WOERDEN, V. F. What a Waste 2.0: A Global Snapshot of Solid Waste Management to 2050. Urban Development Series. Washington, DC: World Bank, [2018]. Disponível em: https://openknowledge.worldbank.org/handle/10986/30317. Acesso e: 27 nov. 2018.

LAYRARGUES, P. P. Sistemas de gerenciamento ambiental, tecnologia limpa e consumidor verde: a delicada relação empresa-meio ambiente no ecocapitalismo. Revista de Administração de Empresas, São Paulo, v.40, p.80-88, abr./jun. 2000. Disponível em: https://www.scielo.br/j/rae/a/D7NndcxFtHsrwdLwS49rXwH/?lang=pt\&format=pdf. Acesso em: 2 jun. 2019.

LEE TAN, A. Financing the Demise of Waste Worker Livelihood, Community Health, and Climate [2009]. Disponível em: https://www.no-burn.org/wp-content/uploads/CleanDevelopment-Mechanism-Flyer.pdf. Acesso em: 12 maio 2018.

MEDINA, M. Reciclaje de desechos sólidos en América Latina. Fronteira Norte, v. 11, n. 21, p. 7-31, jan/jun. 1999. Disponível em:

https://pdfs.semanticscholar.org/0285/74b8532560b36e80fo683db8e00255f268c7.pdf.

Acesso em: 15 out. 2019.

MÉSZÁROS, Í. A montanha que devemos conquistar: reflexões acerca do Estado. São Paulo: Boitempo Editorial, 2015, 191p.

MOVIMENTO NACIONAL DE CATADORES DE RECICLÁVEIS (MNCR). Quantos Catadores existem em atividade no Brasil? São Paulo, 10 abr. 2019a. Disponível em:

http://www.mncr.org.br/sobre-o-mncr/duvidas-frequentes/quantos-catadores-existemem-atividade-no-brasil. Acesso em: 22 out. 2019.

MOVIMENTO NACIONAL DE CATADORES DE RECICLÁVEIS (MNCR). Movimentos e entidades denunciam a situação dos Catadores na Comissão Interamericana de Direitos Humanos. São Paulo, 30 ago. 2019b. Disponível em: http://www.mncr.org.br/sobre-omncr/notas-e-declaracoes/movimentos-e-entidades-denunciam-situacao-dos-catadoresna-comissao-interamericana-de-direitos-humanos. Acesso em: 12 maio 2019. 
MOVIMENTO NACIONAL DE CATADORES DE RECICLÁVEIS (MNCR). Falta material reciclável para os catadores. O que a Prefeitura tem com isso? São Paulo, $1^{\circ}$ ago. 2016. Disponível em: http://www.mncr.org.br/noticias/noticias-regionais/falta-materialreciclavel-para-os-catadores-o-que-a-prefeitura-tem-com-isso. Acesso em: 12 maio 2018.

MOVIMENTO NACIONAL DE CATADORES DE RECICLÁVEIS (MNCR). Catadores discursam na Organização Internacional do Trabalho (OIT). Notícias nacionais, São Paulo, 19 jun. 2013. Disponível em: http://www.mncr.org.br/noticias/noticias-regionais/catadoresdiscursam-na-conferencia-internacional-de-trabalhadores. Acesso em: 4 abr.2019.

MOVIMENTO NACIONAL DE CATADORES DE RECICLÁVEIS (MNCR). MNCR faz intensa participação na Cúpula dos Povos/Rio+20. Notícias nacionais, São Paulo, 26 jun. 2012. Disponível em: http://www.mncr.org.br/mncr/noticias/noticias-regionais/mncr-faz-intensaparticipacao-na-cupula-dos-povos-rio-20 . Acesso em: 4 abr. 2019.

MICHELLIS, C. M. Organizações que se beneficiam de projetos MDL no Brasil: uma análise sobre o acesso de pequenas e médias organizações aos mercados de carbono. 2008. Trabalho de Conclusão de Curso (Bacharelado em Gestão Ambiental) - Universidade de São Paulo-USP, São Paulo, 2008.

MISOCZKY, M. C; BÖHM, S. Do desenvolvimento sustentável à economia verde: a constante e acelerada investida do capital sobre a natureza. Cadernos EBAPE. BR, Rio de Janeiro, v. 10, n. 3 p. 546-568, 2012. Disponível em:

http://bibliotecadigital.fgv.br/ojs/index.php/cadernosebape/article/view/5479. Acesso em: 2 jun. 2019.

MOTA, A. E; SILVA, M. das G. e. A questão ambiental e o contraditório discurso da sustentabilidade. Revista Praia Vermelha, Rio de Janeiro v. 19,p. 37-50, 2009.

MOTA, A. F; SILVA, M. G; VALENÇA, M. RODRIGUES, M; BEZERRA, P. Capitalismo contemporâneo e meio ambiente: as indústrias de reciclagem, o trabalho do catadores de lixo e ação do estado. In: RUIZ, Ana (Coord.). Buquédas Del Trabajo Social

LatinoAmericano- urgencia, propuestas y posibilidade. 1. ed. Buenos Aires: Espacio, 2005. Disponível em: http://www.ts.ucr.ac.cr/binarios/congresos/reg/slets/slets-018-025.pdf. Acesso em: 2 ago. 2018.

NASCIMENTO, M. C. B. N; FREIRE, E. P; DANTAS, F. S. GIANSANTE, M.B. Estado da arte dos aterros de resíduos sólidos urbanos que aproveitam o biogás para geração de energia elétrica e biometano no Brasil. Eng Sanit Ambient, São Paulo, v. 24, n. 1, p. 143-155, 2017. Disponível em: https://www.scielo.br/scielo.php?script=sci_arttext\&pid=S141341522019000100143\&lng=en\&nrm=iso\&tlng=pt. Acesso em: 2 jun. 2019.

ORGANIZAÇÃO DAS NAÇÕES UNIDAS (ONU). Um círculo virtuoso: a integração de catadores na gestão de resíduos sólidos. Brasília (DF), [2016]. Disponível em: https://akatu.org.br/um-circulo-virtuoso-a-integracao-de-catadores-na-gestao-deresiduos-solidos/. Acesso em: 21 de out. 2018. 


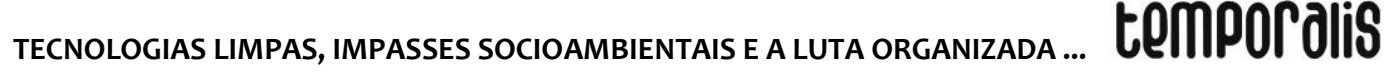

ORGANIZAÇÃO DAS NAÇÕES UNIDAS (ONU). Why does Green economy matter?. [2015]. Disponível em: https://www.unep.org/explore-topics/green-economy/why-does-greeneconomy-matter. Acesso em: 28 fev. 2019.

POLZER, V. Desafios e Perspectivas rumo ao gerenciamento integrado de resíduos nas cidades brasileiras: contribuições a partir de estudos de caso Europeu. 2017. Tese [Doutorado em Arquitetura e Urbanismo]-Universidade Presbiteriana Mackenzie. São Paulo. 2017.

ROCHA, M. T. Aquecimento global e o mercado de carbono: uma aplicação do modelo CERT. 2003. Tese (Doutorado em Agronomia)- Escola Superior de Agricultura Luiz de Queiroz, Universidade de São Paulo, São Paulo, 2003.

ROCHAFORTE. Multinacionais estão de olho no lixo dos aterros sanitários do Brasil. Informativos e Notícias, Sorocaba, $1^{\circ}$ out. 2015. Disponível em: https://www.rochafortesaneamento.com.br/noticias/multinacionais-estao-de-olho-nolixo-dos-aterros-sanitarios-do-brasil/20130924-092912-K313. Acesso em: 7 set. 2018.

SANTOS; DIAS, G; MENDONÇA, M;P;TEODÓSIO, A. Frames de ação coletiva: uma análise da organização do Movimento Nacional de Catadores de recicláveis no Brasil (MNCR). In: SCHERER-WARREN, I.; LÜCHMANN, L. H. H. Movimentos sociais e participação: abordagens e experiências no Brasil e na América Latina. Florianópolis: UFSC, 2011.

SEVERI, F. C. Os catadores de materiais recicláveis e reutilizáveis na Política Nacional de Resíduos Sólidos. Revista Direito e Praxis, São Paulo, v. 5, n.1, 2014. Disponível em: https://www.e-publicacoes.uerj.br/index.php/revistaceaju/article/view/9437/9249. Acesso em: 20 jan. 2020.

SILVA, M. G. Questão Ambiental e desenvolvimento sustentável: um desafio ético político ao serviço social. 1. ed. São Paulo: Editora Cortez, 2010.

TUBINO, N. Catadores de recicláveis, contra higienização. Jornal Carta Maior, São Paulo, 19 jun. 2012. Disponível em: https://www.cartamaior.com.br/?/Editoria/MaeTerra/Catadores-de-reciclaveis-contra-higienizacao/3/25323. Acesso em: 12 mai. 2018.

VANDERMERWE, S.; OLIFF, S. Customers drive corporations green. Long Range Planning, V. 23, n. 6, p. 10-16, 1990.

VRYENHOEK, L. Catadores de materiais recicláveis ingressam na cena global. [S.I.]: Wiego, ago. 2011. Disponível em: https://www.wiego.org/resources/catadores-demateriais-recicl\%C3\%A1veis-ingressam-na-cena-global. Acesso em: 12 Mai. 2018..

WOMEN IN INFORMAL EMPLOYMENT: GLOBALIZING AND ORGANIZING (WIEGO). Waste Pickers. Economia Informal. [2015]. Disponível em: http://www.wiego.org/informaleconomy/occupational-groups/waste-pickers. Acesso em: 4 abr. 2019.

WIEGO - WOMEN IN INFORMAL EMPLOYMENT: GLOBALIZING AND ORGANIZING. Estudo de Monitoramento Econômico Informal. The urban informal workforce: collectors / 


\section{temPOP Olif cotrim, geIzIANE SILva; PERUZZo, JULIANE FEIX}

recyclers. [2014]. Disponível em

https://www.wiego.org/sites/default/files/publications/files/IEMS-waste-picker-report.pdf.

Acesso em: 4 abr. 2019.

Geiziane Silva Cotrim Trabalhou na concepção e delineamento, na análise e interpretação dos dados, assim como na redação do artigo.

Mestra em Serviço Social pela Universidade Federal de Pernambuco (UFPE). Especialista em Saúde Coletiva pelo Programa de Residência Multiprofissional em Saúde Coletiva da Secretaria de Saúde do Recife. Servidora Pública atuando como Assistente Social no Núcleo de Atenção à Saúde do Adolescente (NASA), em transição para o Centro de Atenção Psicossocial Infantojuvenil (CAPSi) - Paulista/Pernambuco e Assistente Social na Maternidade do Hospital Agamenon Magalhães - Recife (PE).

Juliane Feix Peruzzo Trabalhou na concepção e delineamento, na redação do artigo, bem como na revisão crítica.

Assistente Social. Doutora em Serviço Social pela Pontifícia Universidade Católica do Rio Grande do Sul. Docente da Graduação e Pós-Graduação do Departamento de Serviço Social da Universidade Federal de Pernambuco (UFPE). 